\title{
A COMPARATIVE STUDY OF THE EFFECTS OF OPC-1085 AND PROPRANOLOL ON ISOLATED GUINEA PIG ATRIUM
}

\author{
Issei IMANAGA, Yasuzi SAKAMOTO and Tadao TOMITA \\ Department of Physiology, School of Medicine, \\ Fukuoka University, Fukuoka 814, Japan
}

Accepted October 6, 1976

\begin{abstract}
Effects of a newly synthesized beta-blocker, 5-(3-tert-butylamino-2-hydroxy) propoxy-3,4-dihydrocarbostyril (OPC-1085) were compared with those of propranolol. OPC-1085 had a potency about 3 times greater than that of propranolol in blocking the positive inotropic and chronotropic effects of isoprenaline on the isolated guinea pig atrium. At a concentration of over $3 \times 10^{-5} \mathrm{M}$, OPC- 1085 produced negative inotropic and chronotropic effects. However, these effects were about 10 times weaker than those of propranolol. Suppressing effects on the rate of rise and on the maximum driving frequency of action potentials were also more than 10 times less than those of propranolol. There was almost no change in the action potential of vagus nerve after a $10 \mathrm{~min}$ treatment with OPC-1085 $\left(10^{-5} \mathrm{M}\right)$, while the action potential was reduced to $60-70 \%$ with propranolol $\left(10^{-5} \mathrm{M}\right)$.
\end{abstract}

For investigations on the mechanism of catecholamine action, it is useful to use an agent which blocks the action. The blocker should block specifically the catecholamine action and should not have any other action. However, it is known that some beta-receptor blocking agents, such as propranolol and pronethalol, have local anesthetic actions $(1,2,3$, 4). Although there are beta-blockers which are nearly devoid of local anesthetic activity (Practolol: (4); N-isoprophyl-p-nitrophenyl-ethanolamine: (5)), it is interesting to compare potencies of beta-blocking action and of local anesthetic action in other agents.

The aim of the present experiments was to investigate these points for a newly synthesized beta-blocker, OPC-1085 (5-(2-hydroxy-3-tert-butylamino) propoxy-3,4-dihydrocarbostyril hydrochloride $(6,7)$. It has been reported that the local anesthetic action of OPC-1085 is about one tenth that of propranolol in the dorsal skin response of the guinea pig (8). In the present experiments, isolated preparations of the guinea pig atrium and vagus nerve were used to observe the suppressing action, and the action of OPC-1085 was compared with that of propranolol.

\section{MATERIALS AND METHODS}

Guinea pigs weighing $300-400 \mathrm{~g}$ were stunned and bled, and the hearts were quickly removed. The right atrium from each animal was excised and mounted in an organ bath containing $4 \mathrm{ml}$ Krebs solution of the following composition (mM): $\mathrm{NaCl} 120, \mathrm{KCl} 5.9$, $\mathrm{CaCl}_{2} 2.5, \mathrm{MgCl}_{2} 1.2, \mathrm{NaHCO}_{3} 15.5$, Glucose 11.5 . A gas mixture of $3 \% \mathrm{CO}_{2}$ and $97 \%$ $\mathrm{O}_{2}$ was bubbled through the solution which was kept at $37^{\circ} \mathrm{C}$. Vigorous bubbling of the gas was critical for maintaining a steady magnitude of the contractions. Spontaneous 
contractions were isometrically recorded by using a strain gauge transducer and a polygraph. In some experiments, the left atrium was used for the mechanical and also electrical recordings, keeping the driving frequency constant at 120/min. The preparation was stimulated by $0.5-3 \mathrm{mscc}$ pulses of supramaximal intensity. The results with the left atrium were essentially the same as those with the right atrium.

Krebs solution was allowed to flow continuously through the organ bath at a constant rate of $1.5 \mathrm{ml} / \mathrm{min}$. Drugs were usually added directly to the organ bath, so that the drug concentration was maintained only transiently after injection and then gradually diluted by a constant flow of Krebs solution. When the blocking action of isoprenaline effects was tested, the blockers were applied to the rescrvoir to keep the concentration constant, and isoprenaline was administered after 10-20 min exposure to the blocker.

For intracellular recording of the action potential of the atrium muscle, a conventional method was used. A nicro-electrode of 30-60 M $\Omega$ was connected to FET pre-amplifier, and the action potentials, spontaneously generated or driven by electrical stimulation, were displayed on the oscilloscope and recorded on film. For recording of the action potential of the guinea pig vagus nerve, the sucrose-gap method (9) was used. The action potentials were evoked by supramaximal stimulation of $0.5 \mathrm{msec}$ current pulses at a frequency of $0.2 \mathrm{H} z$.

Drugs used were (-)-5-(3-fort-butylamino-2-hydroxy) propoxy-3,4-dihydrocarbostyril hydrochloride (OPC-1085, molecular weight: 328.85, Otsuka Seiyaku), ( -)-isoprenaline hydrochloride (Nikken Kagaku) and (-t)-propranolol hydrochloride (Sumitomo Kagakul.

\section{RESULIS}

Suppression of isoprenaline effects by OPC-1085 and propranolot in the guinea pig atrium

Effects of isoprenaline on the isolated atriun varied greatly in magnitude depending on the condition of preparation and the interval of drug application. When the contraction was reduced in the course of experiments, the percentage increase in contraction force by isoprenaline increased considerably. The second application of isoprenaline gave a response smaller than that to the first. This reduction was marked when the concentration was high and the interval of application was short. For example, when $10^{-6} \mathrm{M}$ isoprenaline was

FIG. 1. Mean concentration-effect curves for positive inotropic responses (left) and positive chronotropic responses (right) of guinea pig atria to isoprenaline in the absence (control) and in the presence of propranolol $\left(3: 10^{-7} \mathrm{M}\right)$ and of OPC -1085 $\left(3 \times 10^{-7} \mathrm{M}\right)$. Changes from the control are expressed as percentage. Vertical bars represent S.D. (n $=-11$ ). 
used, the time interval should be longer than $30 \mathrm{~min}$ to give the same response. Therefore, only two different concentrations of isoprenaline were usually tested in each preparation, and the dose response relationship was obtained by averaging the values from 25 preparations.

Fig. I shows the dose-response curve for the positive inotropic (left) and chronotropic effects (right) of isoprenaline in both the absence and presence of $\beta$-blockers, OPC-1085 $\left(3 \times 10^{-7} \mathrm{M}\right)$ and propranolol $\left(3 \times 10^{-7} \mathrm{M}\right)$. Although an exact quantitative analysis was not made in the present experiments, there was a significant difference in the potency between OPC-1085 and propranolol. The $\beta$-blocking action of OPC-1085 was about 3 times stronger than that of propranolol. The difference in potency between OPC-1085 and propranolol was less in the isolated guinea pig atrium than that in the dog heart in vivo, in which OPC1085 was about 30 times stronger than propranolol (7).

Direct effect of OPC-1085 and propranolol on the mechanical response of guinea pig atrium

Although sympathomimetic action of OPC-1085 has been reported in dog hearts (7), this action was weak in the isolated guinea pig atrium. At a low concentration $\left(1-5 \times 10^{-6}\right.$ M), OPC-1085 often increased slightly the contraction and the frequency (Fig. 2a). When the concentration was increased to more than $3 \times 10^{-5} \mathrm{M}$, OPC -1085 produced negative inotropic and negative chronotropic effects ( $b$ and $c$ ). The time course of tension development was little affected during the suppression by OPC-1085. Propranolol reduced the contraction by $20 \%$ with only a concentration of $3 \times 10^{-6} \mathrm{M}$, and the recovery from the suppression was slow. At a concentration of $3 \times 10^{-5} \mathrm{M}$, propranolol reduced the contraction force by $52 \%$ and OPC- 1085 by $12 \%$. At $3 \times 10^{-4} \mathrm{M}$, OPC-1085 suppressed the contraction by $55 \%$. Thus, the suppressing action of OPC-1085 was about 10 times weaker than that of propranolol. The suppressing action by the blockers was potentiated when isoprenaline was previously applied, even after the complete recovery from the effects of

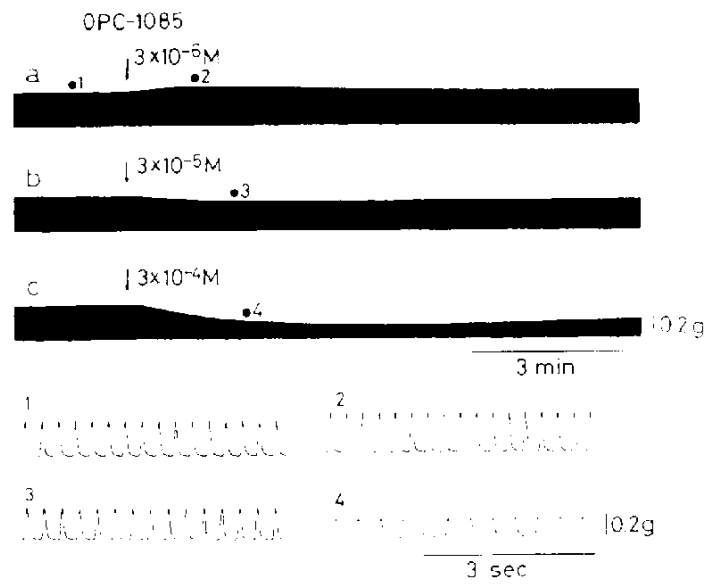

Fici. 2. Efrects of OPC-1085 on spontaneous contractions of the atria. OPC-1085 (a: $3 \times 10^{-6}, b: 3 \times 10^{-5}$ and $c: 3 \times 10^{-4} \mathrm{M}$ ) were applied at the arrows. Lower four records (1 4) taken at at fister speed correspond to the contrations shown by dots with the same number in $a, b$ and $c$, respectively. 
isoprenaline.

Direct effect of $O P C-1085$ and propranolol on the action potential of cardiac muscles

Propranolol is known to reduce the amplitude and the maximum rate of rise of action potential of the guinea pig atrium (2). Effects of OPC-1085 on the action potential were compared with those of propranolol (Fig. 3). There was almost no effect with OPC-1085 up to a concentration of $10^{-6} \mathrm{M}$. but exposure to $10^{-5} \mathrm{M}$ solution for $5 \mathrm{~min}$ produced a weak suppressing effect on the amplitude and the maximum rate of rise without change in the duration of action potential and the resting potential. In these experiments, the right and left atria were used, but there was no significant difference. The maximum rate of rise was reduced from $65 \pm 8 \mathrm{~V} / \mathrm{sec}$ to $55 \pm 6 \mathrm{~V} / \mathrm{sec}(\mathrm{n}=7)$ by $10^{-5} \mathrm{M}$ OPC-1085. On the other hand, propranolol at a concentration of $10^{-5} \mathrm{M}$ markedly suppressed the amplitude, and the maximum rate of rise, as observed in the rabbit atrium (2) (Fig. 3, the lower record). The frequency of spontaneous activity was also reduced. The duration of action potential was pro-

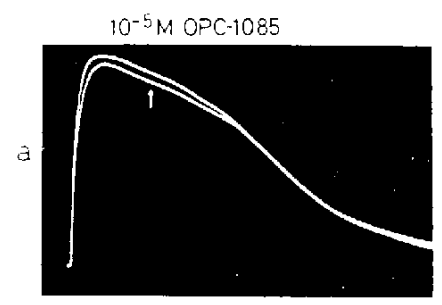

$10^{-5} \mathrm{M}$ Propranolol

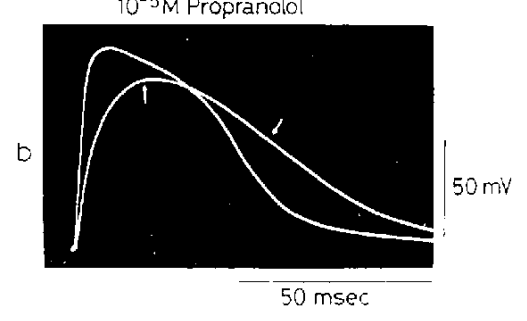

FiG. 3. Effects of blockers (upper trace: $10^{-5} \mathrm{M}$ OPC-1085 and lower trace: $10^{-5} \mathrm{M}$ propranolol) on intracellularly recorded action potential of the right atrium. Control action potential and action potential treated with the blocker for 5 min (shown by arrow) are superimposed.

longed, in contrast to the report for the rabbit atrium after $3 \times 10^{-6} \mathrm{~g} / \mathrm{ml}$ propranolol application (2). The maximum rate of rise of action potentials was reduced from $62 \pm 5$ $\mathrm{V} / \mathrm{sec}$ to $25 \pm 3 \mathrm{~V} / \mathrm{sec}\left(\mathrm{n}=7\right.$ ) by $10^{-5} \mathrm{M}$ propranolol. In Fig. 4 (left), averages of the percentage reduction of the maximum rate of rise obtained with different concentrations of the

Fici, t. Percentage reduction of the maximum rate of rise of action potentials (left) and the maximum driving (requency, at which the action potential followed electrical stimulation (right), with different concentrations of OPC-1085 and propranolol (10 min treatment). left atrium stimulated by 1 msec pulses of stopranaximal inlensity. Vertical bars represent S.D. $(n-7)$. 
blockers are graphically shown.

When the refractory period is prolonged, the maximum driving frequency at which the action potential of atria could follow electrical stimuli is reduced $(2,10)$. This effect on the maximum driving frequency was also much stronger with propranolol as compared with OPC-1085 (Fig. 4, right).

Effects of $O P C-1085$ and propranolot on the action potential of vagus nerve

Local anesthetic actions of OPC-1085 and propranolol were compared by recording the compound action potential of the guinea pig vagus nerve. The action potential was recorded using the sucrose-gap method. Almost no change in this potential was observed after a
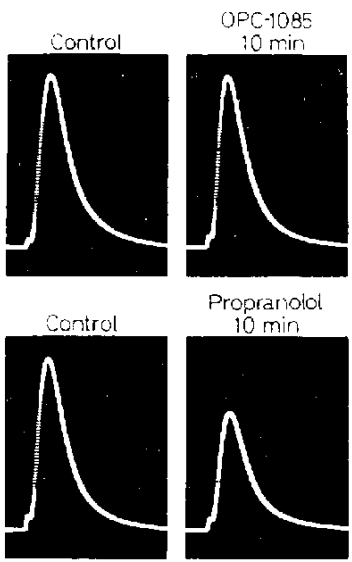

FIG. 5. Action potentials of the guinea pig vagus nerve recorded using the sucrose-gap method. Stimulation $(0.5 \mathrm{msec})$ was applied every 5 sec. Effects of OPC-1085 (upper row, $10^{-5} \mathrm{M}$ ) and of propranolol (lower row, $\left.10^{-5} \mathrm{M}\right)$ treatment $(10 \mathrm{~min})$ and the recovery after a $10 \mathrm{~min}$ washout.

10 min treatment with OPC-1085 $\left(10^{-5} \mathrm{M}\right)$, while the amplitude and the rate of rise of action potential were reduced to $60-70 \%$ after a $10 \mathrm{~min}$ exposure to propranolol $\left(10^{-5} \mathrm{M}\right)$, as shown in Fig. 5. The resting potential remained more or less the same during exposure to the blockers.

\section{DISCUSSION}

OPC-1085 has a potency about 3 times greater than propranolol in blocking the positive and chronotropic effects of isoprenaline on the isolated atrium of guinea pigs. This is in fair agreement with previous observations on the guinea pig atrium (8) and the heart of anesthetized dogs (7). However, the difference in potency seems to be less in the isolated guinea pig atrium than in the dog heart in vivo.

It is well known that propranolol has suppressing effects on the heart muscle $(11,12$, 13). This compound reduces the amplitude and the rate of rise of action potential both in the atrium and the vagus nerve, without affecting the resting potential. Furthermore, the maximum driving frequency is also reduced. All these effects support the postulation that propranolol possesses a local anesthetic action $(2,8)$. OPC-1085 also has similar suppressing effects on isolated guinea pig atrium at concentrations over $10^{-5} \mathrm{M}$, but the potency is at least 10 times less than that of propranolol. This difference as observed with the electrophysiological method is in agreement with data on the local anesthetic activity in guinea pig dorsal skin (8). At a concentration of $10^{-5} \mathrm{M}$, the local anesthetic action of OPC-1085 cannot clearly be observed in guinea pig vagus nerve with a 10 min exposure, while propranolol reduces the action potential by about $30 \%$ at the same concentration. sippression of the mechanical response of the guinea pig atrium by the blockers, propranolol 
and OPC-1085 is thus attributed to the local anesthetic action, because the effective concentration for both actions is similar for each blocker.

Other $\beta$-blockers, such as dichloroisoproterenol (14) and pronethalol (15) have $\beta$ receptor stimulating properties. It has also been reported that an intravenous application of OPC-1085 (about $1 \mathrm{mg} / \mathrm{kg}$ ) produces sympathomimetic effects on the heart of anesthetized dogs (7). However, in the isolated atrium of guinea pig, the sympathomimetic effects of OPC-1085 are weak. It is possible that the sympathomimetic effect on the heart can be more clearly demonstrated in vivo than in vitro.

4-(2-hydroxy-3-isopropylaminopropoxy)-indole (LB-46) is reportedły a $\beta$-blocker which is more potent than propranolol and has weak local anesthetic properties (3). As the suppressing action of OPC-1085 is only slightly less than LB-46 (unpublished observation), the properties of OPC-1085 appear to be quite similar to those of LB-46.

\section{REFERENCES}

1) Gill, E.W. ANd Vaughan Williams, E.M.: Nature 201, 199 (1964)

2) Morales-Agullera, A. And Vaughan Williams, E.M.: Brit. I Pharmacol. 24, 332 (1965)

3) Giudicelli, J.F., Schmitt, H. And Boissier, J.R.: J. Pharmacol. exp. Ther. 168, 116 (1969)

4) Sasa, M., Avner, B.P. and Albuquerque, E.X.: Europ. J. Pharmacol. 23, 97 (1973)

5) Hahn, R.A., Pendleton, R.G. And Wardell, J.R. : J. Pharmacol. exp. Ther. 161, 111 (1968)

6) Nakagawa, K., Murakami, N., Yoshizaki, S., Tomonaga, M., Mori, H., YabuUchi, Y. AND ShIntani, S.: J. med. Chem. 17, 529 (1974)

7) Yabuuchi, Y. And Kinoshita, D.: Japan. J. Pharmacol. 24, 853 (1974)

8) Sfiktya, A., Yamamoto, J., Maekawa, H., Nagae, M., Kato, Y., Suzuki, K., Kojima, Y. And Karasawa, R.: Pharmacometrics 9, 357 (1975)

9) Straub, R.W.: J. Physiol. 135, 2 (1956)

10) Sekiya, A. and Vaughan Williams, E.M.: Brit. J. Pharmacol, 21, 473 (1963)

11) Nakano, J. ANd Kusahari, T.: Am. J. Physiol. 210, 833 (1966)

12) Blinks, J.R.: Ann. N.Y. Acad. Sci. 139, 673 (1967)

13) Parmley, W.W. and Braunwald, E.: $J$. Pharmacol. exp. Ther. 158, 11 (1967)

14) Moran, N.C. and Perkins, M.E.: J. Pharmacol. exp. Ther. 124, 223 (1958)

15) Black, J.W., Duncan, W.A.M. aNd Shanks, R.G.: Brit. J. Pharmacol. 25, 577 (1965) 